\title{
PARCEIROS NA ESCOLA: FAMÍLIA E ESCOLA JUNTOS NO PROCESSO DE ENSINAR E APRENDER DAS CRIANÇAS
}

\section{Luciana Soares MUNIZ ${ }^{1}$}

\begin{abstract}
RESUMO: As experiências da criança para além do contexto escolar constituem fontes que podem alicerçar o trabalho no cotidiano escolar com os componentes curriculares. Dessa forma, o presente texto tem como objetivo principal relatar a experiência de um projeto realizado em uma turma de 20 ano do Ensino Fundamental, na Escola de Educação Básica da Universidade Federal de Uberlândia-MG. O projeto teve como foco central possibilitar e contribuir para o processo de ensino e aprendizagem dos alunos do $2^{\circ}$ ano, com a participação da família na escola. Como metodologia, foi utilizado o diálogo com os envolvidos no projeto, crianças, familiares e professores, para a elaboração e planejamento das aulas a serem realizadas pelos referidos participantes na escola. De forma geral, o desenvolvimento do projeto favoreceu o vínculo entre família e escola, assim como oportunizou processos de aprendizagem significativos para as crianças de conteúdos curriculares que, muitas vezes, não se configuram como elementos da própria vida da criança.
\end{abstract}

Palavras-Chave: Aprendizagem, Família, Escola.

\section{INTRODUÇÃO}

O presente texto tem como objetivo principal relatar a experiência de um projeto realizado em uma turma de $2^{\circ}$ ano do Ensino Fundamental, na Escola de Educação Básica (Eseba), da Universidade Federal de Uberlândia-MG (UFU),

1 Docente no Colégio de Aplicação (ESEBA/UFU) da Universidade Federal de Uberlândia. 
no ano de 2009. Para isso, iniciei com a apresentação de algumas informações importantes para o leitor, uma vez que necessárias se fazem para compreensão de todo o processo da experiência vivenciada.

Sempre me preocupei com a distância entre os componentes curriculares trabalhados diariamente pela escola e as vivências dos alunos nos diversos espaços da sociedade. Os Parâmetros Curriculares Nacionais (1997) também discorrem sobre essa problemática. Esta inquietação me levou a observar que as crianças de sete e oito anos, nos vários diálogos em sala de aula, traziam como referência principal suas vivências familiares.

Optei pela perspectiva histórico-cultural, como base para o desenvolvimento do projeto, para a qual os sujeitos envolvidos no processo de ensino e aprendizagem são permeados por uma cultura e uma história que é singular e por isso própria de cada um (VYGOSTKY, 1985). Desta forma, a aprendizagem dos conteúdos curriculares é um processo que participa da vida da criança e está associada 
às suas experiências tanto no contexto escolar, quanto para além do mesmo.

Educar nesse sentido é contextualizar as ações da escola à sociedade como um todo e possibilitar que os alunos vivenciem uma educação na vida. Assim como destaca Freire (1997), educar é criar consciência crítica e formar um cidadão em cada um de seus alunos. Formar um cidadão é possibilitar que os alunos se percebam enquanto sujeitos de seu processo de aprendizagem.

Conforme o Art.53 do Estatuto da Criança e do Adolescente (1990), a criança e o adolescente têm direito à educação, visando ao pleno desenvolvimento de sua pessoa. Dessa forma, a educação se torna um dever social, ou seja, abrange as diferentes instâncias experienciadas pela criança e pelo adolescente, o que demonstra a parceria e a corresponsabilidade da família e da escola nesse processo.

\section{DESCRIÇÃO DO PROJETO}

\subsection{Objetivo do projeto}


Contribuir com o processo de ensino e aprendizagem dos alunos do $2^{\circ}$ ano, com a participação da família na escola.

\subsection{Etapas do projeto}

\subsubsection{Etapa1 - Construção do projeto com os sujeitos envolvidos}

Para iniciar o projeto, o qual foi denominado "Parceiros na Escola", utilizei os momentos de reuniões mensais e atendimentos individuais semanais com as famílias, os quais são oportunizados pela instituição. Também recorri ao dia a dia de sala de aula, durante o mês de março de 2009, para apresentar a proposta e ouvir as possíveis sugestões dos familiares e alunos quanto à organização e viabilidade do projeto a ser realizado ao longo do ano letivo.

\subsubsection{Etapa 2 - Sondagem: levantamento dos eixos de interesse dos familiares e alunos}

Com o apoio dos familiares da turma na viabilização do projeto, iniciei em abril uma sondagem, por meio de 
diálogos com os participantes, acerca das atividades que os mesmos realizavam em seu dia a dia, tais como: profissão, experiências e vivências nos diferentes espaços sociais, e que pudessem vir a contribuir com os componentes curriculares trabalhados no $2^{\circ}$ ano do Ensino Fundamental.

Dessa forma, verifiquei que as atividades profissionais dos participantes, bem como algumas experiências, apresentavam estreita relação com as vivências e componentes curriculares desenvolvidos na escola. Com a sondagem, observei uma aproximação que alguns dos temas sugeridos pelos familiares e alunos apresentavam entre si e, diante dessa identificação, foi possível o trabalho em grupo de alguns envolvidos para preparação da atividade a ser realizada.

\subsubsection{Etapa 3 - Planejar com os familiares e alunos as atividades a serem desenvolvidas}

Após a etapa de sondagem e diante das temáticas a serem abordadas com os alunos iniciei, ainda no primeiro semestre do ano de 2009, a preparação junto aos familiares das atividades a serem realizadas com a turma. 
Para isso, organizei momentos de reuniões individuais com os referidos participantes, em um processo que envolveu estudo da temática e preparação do material a ser utilizado na aula. Foram dois a três encontros antes da realização da aula.

\subsubsection{Etapa 4 - A aula}

Cada aula foi organizada e estruturada de acordo com a singularidade de cada familiar e da turma como um todo. Todas as aulas foram realizadas no segundo semestre do ano letivo de 2009. Descrevo abaixo a temática abordada, algumas vivências durante a aula e as formas diferenciadas que a turma registrou cada momento da realização do trabalho.

Uma das aulas foi denominada "Uma vivência no Laboratório de Ciências". A turma teve a presença de duas mães que atuavam na área de saúde. A experiência ocorreu no Laboratório de Ciências da própria escola e envolveu a temática "Corpo Humano". Tive a oportunidade de conhecêlas melhor e saber que trabalhavam como fisioterapeutas. As crianças ficaram divididas em grupos e em cada grupo 
havia várias partes do interior do corpo humano, feitos de material plástico: o Sistema Circulatório, Sistema Respiratório, Sistema Digestivo, Sistema Endócrino, Sistema Esquelético e o Sistema Nervoso. Após manipularem os objetos, as crianças elaboraram perguntas e as mães foram respondendo. Ao final do trabalho, os alunos tiveram a oportunidade de agradecer a presença dos familiares e demonstraram o quanto haviam aprendido.

Em outra aula, denominada "Gestação", estiveram presentes três mães que iriam tratar da temática gestação. Levei a turma para a sala da biblioteca, e foram utilizados data-show e DVD. No momento de apresentação das participantes, elas relataram que duas delas haviam tido gestação a menos de um ano e estavam com seus bebês ali presentes e a outra estava grávida de sete meses. Elas fizeram uma aula com imagens da criança no útero e após o nascimento do bebê. A turma teve a oportunidade de assistir a uma filmagem do exame de ultrassom, no período de gestação. Foram enfatizados os cuidados com os bebês, envolvendo higiene e alimentação. A aula oportunizou a 
descoberta do crescimento da barriga durante a gestação e dos movimentos que o bebê faz dentro da barriga e são sentidos pela mãe.

Outra aula foi denominada "Curiosidades sobre o Japão". Um aluno da turma era descendente de japonês e relatava, com frequência, fatos familiares que retratavam costumes japoneses. Assim, sua mãe e sua irmã foram à escola, falar um pouco mais sobre a cultura do Japão. Levaram revistas, livros, fotos que ilustraram as discussões sobre o Japão. Falaram algumas palavras japonesas, como: arigatô (palavra utilizada para agradecer) e sayonara (palavra utilizada para despedir de alguém). Aproveitaram a aula para ensinar aos alunos como fazer um origami de papel do pássaro Tsuro, símbolo da sorte no Japão, bem como a utilizar o hashi, que se refere a dois pedaços de madeira usados, na tradição japonesa, para levar o alimento até a boca. A turma foi presenteada com um hashi para cada aluno e um desenho, japonês, para ser colorido. Cada aluno recebeu pedaços de papéis coloridos para 
inventar um origami. A aula foi registrada por meio de uma poesia elaborada coletivamente pela turma.

Na aula "Educação para o Trânsito", a turma teve a presença de um pai que exercia o cargo de agente municipal de trânsito, na Secretaria de Trânsito e Transportes (SETTRAN). Ele desenvolveu uma palestra que abordava a temática: educação e segurança no trânsito. Os alunos puderam descobrir e compartilhar as experiências vividas por eles na própria entrada e saída da escola, bem como em outras situações da vida. Pela explicação do pai, os alunos perceberam a real importância da utilização do cinto de segurança, do uso do capacete, do pedestre atravessar uma rua pela faixa de pedestre, do respeito aos sinais de trânsito e outras situações de trânsito. 0 momento foi aproveitado com um passeio da turma pelo quarteirão da escola para experienciar o aprendido.

Outra importante aula foi denominada "A música em nossas vidas", a qual contou com o apoio de uma mãe, pai e irmão de um de nossos alunos. Os pais relataram a experiência de confeccionar dois livros de músicas com 
seus filhos ao longo da vida de cada um. Sendo assim, explicaram que a cada dia em que seus filhos aprendiam uma música infantil, esta era registrada no livro. Algumas letras já eram conhecidas pelas crianças e outras foram apresentadas. O grupo também cantou músicas que não havia no livro. Houve troca de saberes entre a família e os alunos. Todos cantaram e dançaram as músicas que fizeram parte das várias etapas de vida da criança. Ao final da aula, o pai, a mãe e o irmão do aluno presentearam a turma com pipoca e brigadeiro, foi uma verdadeira festa.

Uma mãe, professora, trabalhou em sua aula um jogo chamado "Caça ao Tesouro", com o objetivo de explorar o sistema de numeração decimal. A mãe iniciou a aula mostrando para a turma uma caixa, toda enfeitada, dizendo que dentro dela havia um tesouro, mas que só ganharia o tesouro o aluno que conseguisse vencer o jogo proposto. Ela explicou as regras do jogo, que consistia em utilizar dois dados, sendo um para representar unidades e outro para dezenas. Organizadas em duplas, cada criança jogava um dado de cada vez, sendo que para o primeiro 
dado o participante marcava a quantidade em unidades e o segundo dado jogado representava a quantidade em dezenas. As crianças marcavam o resultado, obtido em cada dado, em uma folha de papel e faziam a soma para descobrir o número formado. Ao final, apenas um aluno foi o vencedor e este ganhou o tesouro e teve uma surpresa. Dentro da caixa havia uma instrução de que seu conteúdo deveria ser dividido com a turma. E, assim, a dupla dividiu os pirulitos e balas com todos os colegas.

Outra aula, intitulada de "Forças Armadas e Bandeira do Brasil", foi realizada pelo pai de um aluno da turma que era soldado do Exército. Ele aproveitou seus conhecimentos e o interesse do grupo para fazer uma apresentação de algumas curiosidades do cotidiano de um quartel, demonstrando com imagens, por meio do data show, suas experiências como soldado. Aproveitou o dia da Bandeira para trabalhar o significado das estrelas pintadas na Bandeira do Brasil, bem como a frase escrita na mesma. Apresentou aos alunos o hino da Bandeira, mostrando a letra do hino e depois, utilizando aparelho de som, 
disponibilizou para a turma o hino cantado. Os alunos tiveram muitas perguntas e dúvidas e foram dialogando, ao longo de toda a aula, com o pai. O registro da aula foi feito com o desenho da Bandeira do Brasil.

No dia do aniversário de uma aluna, a mãe fez uma festa na sala de aula e aproveitou este momento para fazer sua aula denominada "Como organizar uma festa de aniversário?". Ela conversou com a turma sobre o que é necessário para realizar uma festa de aniversário. Em um diálogo constante com os alunos, a ministrante da aula relatava que foi preciso organizar convites e saber os nomes dos convidados, neste caso os próprios alunos. Utilizou o convite da filha para ilustrar sua fala e apresentou aos alunos o que precisa constar no convite, como: data, local, horário e outras informações. A mãe trabalhou a questão da comida, que é preciso saber a quantidade de convidados para definir o peso do bolo, a quantidade de salgados, doces e outros itens da festa. Falou da importância de não desperdiçar alimentos, bem 
como dos cuidados com a higiene do local antes, durante e após a comemoração.

Em continuidade ao projeto, a turma experienciou a aula intitulada "A Matemática do dia a dia", que foi desenvolvida por duas mães de alunos, as quais atuavam na profissão de vendedoras, sendo que uma mãe trabalhava com telemarketing e a outra como vendedora autônoma de roupas e sapatos. As mães levaram produtos para simularem situações de comercialização dos mesmos. Falaram das formas de atendimento ao cliente, seja por telefone ou mesmo pessoalmente, trabalharam com 0 grupo as diferentes formas de pagamento (cheques, cartões de crédito e débito, dinheiro e outras); bem como proporcionaram várias situações de compra e venda em que todos participavam como clientes e também como vendedores, fazendo cálculos, recebendo o pagamento e até voltando troco, para demonstrarem o que estava sendo explicado. Durante a aula elas possibilitaram uma vivência lúdica em que simularam uma venda, pelo telefone, de balas. Assim, todos vivenciaram o papel de compradores, 
de vendedores ou de entregadores das balas. Essa aula foi registrada pelos alunos com a montagem de um panfleto, feito com recorte de revistas e colagem de imagens de objetos. Os alunos simularam preços dos produtos e até criaram um nome para o estabelecimento onde os produtos eram encontrados para compras.

Aproveitando a temática sobre "Vendas" e o fato de uma mãe não poder comparecer à escola para vivenciar esse momento, por causa do trabalho, combinei, com a ministrante da aula e a aluna da escola, que iria até o local de trabalho da mesma, uma loja de artigos para presentes, e faria uma filmagem que demonstrasse uma situação de venda. Tal filmagem foi assistida e discutida em sala de aula pelos alunos. A mãe disponibilizou o cartão da loja para os 25 alunos e, na oportunidade, foi trabalhado com a turma esse gênero textual. O registro da aula foi realizado com um desenho que ilustrou a maneira como uma loja pode ser organizada, tendo em vista os produtos que são oferecidos na mesma. 
Em outra aula, denominada "Limpeza do ambiente em que vivemos: vamos ajudar?", a turma recebeu a visita de uma mãe e duas avós, que abordaram o tema da importância da higiene com a casa. Elas se apresentaram ao grupo e relataram que eram donas de casa. Levaram para a sala de aula objetos utilizados no dia a dia para limpar uma casa, tais como: vassoura, rodo, panos para limpar chão e móveis, detergente, sabão em quadro, sabão em pó, amaciante para roupa, balde e outros. Abordaram a importância de manter a casa organizada e os brinquedos guardados após brincar. Falaram dos cuidados que todos e, principalmente, as crianças precisam ter com os produtos de limpeza que são tóxicos. Os alunos foram fazendo perguntas que permeavam parte de suas vivências em casa e os familiares ali presentes foram dialogando com a turma.

Outra interessante aula foi denominada "Cuidando da higiene do corpo", realizada por uma mãe de uma das crianças da turma. Ela se apresentou e disse estar ali para falar da importância dos hábitos de higiene na escola e em qualquer outro lugar. A turma foi conduzida ao local em 
que se lavavam as mãos na escola. A ministrante da aula pediu que cada aluno fizesse uma demonstração da forma como lavam as mãos todos os dias. Após esse momento, a mãe, dona de casa, fez uma explicação lavando suas mãos e aproveitou para trabalhar com a turma a relevância da economia de água. Os alunos foram observando e fazendo perguntas sobre os momentos de lavar as mãos, como antes e após as refeições, ao utilizarem o banheiro, dentre outros. A mãe relatou algumas situações em casa de desperdício de água durante o banho, nos momentos de escovação, e falou da importância de cada momento desse para nossa saúde.

Em outra aula intitulada "Higiene pessoal", uma mãe, a qual era cabeleireira, apresentou para a turma algumas curiosidades sobre a higiene com cabelo e unhas. Ela iniciou a aula falando de sua profissão: cabeleireira. Levou para a sala de aula produtos que utiliza em seu trabalho, tais como: xampu, condicionador, tesoura para unha e cabelo, pente, escova, secador de cabelo, escovinha para lavar as unhas, lixa de unha e pé, dentre outros. Ela 
explicou a importância de manter os cabelos limpos e falou dos piolhos, que são prejudiciais para nossa saúde. Demonstrou a forma de lavar os cabelos sem machucar o couro cabeludo. Falou da importância de manter as unhas aparadas e limpas. Os alunos fizeram perguntas e, após as explicações, a mãe presenteou cada aluno com uma escova para lavarem as unhas. O grupo de alunos fez os agradecimentos e registrou esse momento por meio de um gráfico. O gráfico foi feito partindo das seguintes perguntas à turma: quantos alunos lavam o cabelo na água fria? Quantos lavam o cabelo na água morna? Foi elaborada uma legenda e um gráfico com as informações das questões.

Em outra aula denominada "Higiene bucal: dentes saudáveis", esteve presente um pai de uma aluna, o qual era dentista. Utilizando fantoches que representavam dentes, escova e até a cárie, o pai conversou com a turma sobre a importância e os cuidados com os dentes. Falou da necessidade da escovação e da forma como esta deve ser feita. 
Em outra oportunidade, os alunos experienciaram a aula denominada "Um pouco de Inglês". Os alunos tiveram a oportunidade de aprender, com a mãe de um colega da turma, os numerais de um a dez e alguns nomes de frutas conhecidas pelas crianças, na língua inglesa. A mãe utilizou cartazes e painéis para ilustrar a aula e realizou brincadeiras que envolveram os alunos. Aproveitou a aula para ensinar o grupo a cantar a música "Parabéns", conhecida pelos alunos, em inglês. A turma demonstrou conhecer muito da língua inglesa, trazendo suas vivências, nos diferentes espaços sociais em que encontram palavras escritas e ditas em inglês. Essa aula foi registrada por meio do desenho e escrita em inglês de algumas frutas.

"História de vida" foi outra aula experienciada pela turma. Anteriormente à chegada da mãe, os alunos estavam organizados em círculo na sala de aula para ouvir uma bela história. Ela se apresentou e começou a contar a história de vida de seu filho que teve que lutar muito para conseguir viver. Contou que a criança nasceu de sete meses e que ficou alguns meses na Unidade de Terapia 
Intensiva (UTI). Relatou os cuidados que teve nos primeiros meses de vida e que depois ele ficou bem e tem hoje uma vida tranquila. Destacou momentos engraçados que já viveu e momentos recentes de superação. As crianças ouviram a história com toda atenção e envolvimento. Cada aluno teve oportunidade de dialogar com os colegas e com a mãe, além de agradecê-la pelas suas contribuições. 0 registro dessa aula foi feito com a escrita de uma das histórias engraçadas que a mãe contou sobre o colega.

Em uma tarde a turma recebeu a visita dos pais e da irmã de um dos alunos de sala que tem necessidades especiais (atraso no desenvolvimento neuro-psicomotor). Essa aula foi denominada como "Crianças com necessidades especiais: respeito à singularidade". Os familiares chegaram e se apresentaram para a turma. Falaram das necessidades especiais do filho e da filha, bem como da forma como a filha se alimenta hoje, utilizando sonda. Destacaram a importância de todos serem tratados com amor e respeito. Relataram os hábitos de higiene com os alimentos e com o corpo para a saúde. Os alunos foram 
fazendo perguntas de acordo com as suas curiosidades e demonstraram uma atitude de respeito ao tema tratado. Foram feitos agradecimentos e também houve um momento para brincar com a irmã do colega. O registro foi feito, a pedido da turma, por meio de um desenho que sintetizasse o momento vivido.

A aula "As letras e suas formas", em que esteve presente uma mãe cuja profissão consistia em confeccionar convites de casamento, aniversário e outros eventos, possibilitou aos alunos um estudo sobre caligrafia. Dessa forma, ela apresentou as diferentes possibilidades de escrita de uma mesma letra. Utilizou como recurso visual cartazes para ilustrar sua aula, bem como fez uso da lousa para demonstrar à turma a escrita das letras. Ao final, incentivou o grupo a inventar uma escrita para a primeira letra do nome de cada um. Depois, presenteou a turma, escrevendo com uma caneta de pena o nome de cada aluno. Nessa aula, foi utilizada como forma de registro a escrita de cada letra do alfabeto, de forma personalizada. 
A aula "Meio ambiente" foi ministrada pelo pai e pela mãe de um aluno da turma, que trabalhavam em uma empresa que coletava entulho e fazia a separação dos materiais contidos no mesmo. Foi realizada uma aula no local onde ocorre a separação do entulho e os alunos observaram os materiais que prejudicam e os que fazem bem ao solo. A mãe e o irmão do aluno trabalharam um vídeo de conscientização com relação aos cuidados com o meio ambiente. Após o vídeo, as crianças conheceram o local e fizeram observações sobre os entulhos e a separação dos mesmos pela empresa. A turma degustou um delicioso café da manhã e brincou em uma casinha feita com materiais recolhidos nos entulhos.

Diante do exposto, é possível fazer alusão a Freire (2011), tendo em vista que o presente projeto provocou uma educação favorecedora do pensar a si mesmos e do mundo de forma simultânea, ou seja, as crianças experienciaram na escola o que vivenciavam em outros contextos. Experiência que favoreceu unir e tornar exequível o conteúdo curricular vigente na escola. 


\subsubsection{Etapa 5 - Avaliação da turma e da família do momento vivenciado}

Ao final de cada aula, professora, alunos e familiares relatavam como havia sido aquele momento de aprendizado. O aluno, que contou com a presença de seu familiar na escola, inventava a forma de registrar a experiência e, assim, a turma toda realizava a atividade de acordo com a escolha do colega. Foram elaborados registros diferenciados, tais como: desenho, gráfico, poesia, letra de uma música, texto, relatório, recorte e colagem, criação de história em quadrinhos, dentre outros. Cada familiar registrava também por escrito o significado do vivido na escola.

\section{CONSIDERAÇÕES FINAIS: UM MOMENTO DE AVALIAÇÃO}

Minha avaliação desse projeto é a mais positiva possível. Demandou trabalho, dedicação, empenho e muita perseverança. Mas foi por acreditar na importância desse tipo de trabalho em sala de aula para o aprendizado dos alunos que busquei envolver cada familiar na atividade a 
ser realizada. Esse projeto foi, sem dúvida, uma autoformação, pois o aprendizado que deixou para mim significou acreditar em uma educação na vida, bem como para a vida. Para os familiares, as avaliações revelaram a satisfação e a relevância deste projeto:

Essa parceria é muito válida, pois possibilita aos pais participarem do ambiente escolar de seus filhos, e assim vivenciar nem que seja um pouco um dia na escola. Acredito que esse momento é de grande importância para nós e nossos filhos, como meu filho disse: 'Mamãe foi um dia inesquecível em minha vida, sempre vou lembrar'. Isso não tem preço, vale a pena nos esforçarmos e desfrutarmos de momentos como esse, aprendemos muito (Mãe de um dos alunos - Aula: "Meio Ambiente").

Como professora e pesquisadora na área da Educação, reconheço que esse projeto teve uma repercussão positiva no cotidiano da sala de aula, pois buscou valorizar a diversidade dos saberes e as variadas experiências e vivências que cada família trouxe para a escola. A hierarquização do conteúdo foi quebrada, foram respeitados os ritmos e tempos de aprendizagem, um respeito à heterogeneidade. 


\section{REFERÊNCIAS}

BRASIL. Parâmetros Curriculares Nacionais ( $1^{a}$ a $4^{a}$ séries). Ministério da Educação, Secretaria de Educação Fundamental. Brasília: MEC/SEF, 1997.

BRASIL. Estatuto da Criança e Adolescente. Lei 8.069, de 13 de julho de 1990. Brasília, 1990.

FREIRE, Paulo. Professora sim, tia não: cartas a quem ousa ensinar. São Paulo: Olho d’ Água, 1997.

FREIRE, Paulo. Pedagogia do oprimido. 50. ed. Rio de Janeiro: Paz e Terra, 2011.

VYGOTSKY, L. S. A formação social da mente. São Paulo: Martins Fontes, 1985. 